The Astrophysical Journal, 534:L215-L217, 2000 May 10

(C) 2000. The American Astronomical Society. All rights reserved. Printed in U.S.A.

\title{
JUPITER: AEROSOL CHEMISTRY IN THE POLAR ATMOSPHERE
}

\author{
Ah-San Wong, Anthony Y. T. Lee, and Yuk L. Yung \\ Division of Geological and Planetary Sciences, California Institute of Technology 150-21, Pasadena, CA 91125 \\ AND \\ Joseph M. AJello \\ Jet Propulsion Laboratory, California Institute of Technology, Pasadena, CA 91109 \\ Received 2000 February 23; accepted 2000 March 31; published 2000 May 4
}

\begin{abstract}
Aromatic compounds have been considered a likely candidate for enhanced aerosol formation in the polar region of Jupiter. We develop a new chemical model for aromatic compounds in the Jovian auroral thermosphere/ ionosphere. The model is based on a previous model for hydrocarbon chemistry in the Jovian atmosphere and is constrained by observations from Voyager, Galileo, and the Infrared Space Observatory. Precipitation of energetic electrons provides the major energy source for the production of benzene and other heavier aromatic hydrocarbons. The maximum mixing ratio of benzene in the polar model is $2 \times 10^{-9}$, a value that can be compared with the observed value of $\left(2_{-1}^{+2}\right) \times 10^{-9}$ in the north polar auroral region. Sufficient quantities of the higher ring species are produced so that their saturated vapor pressures are exceeded. Condensation of these molecules is expected to lead to aerosol formation.
\end{abstract}

Subject heading: planets and satellites: individual (Jupiter)

\section{INTRODUCTION}

The first ring compound, benzene $\left(c-\mathrm{C}_{6} \mathrm{H}_{6}\right.$, also known as $\mathrm{A}_{1}$ in this Letter), was detected on Jupiter by the Voyager Infrared Interferometer Spectrometer (IRIS) experiment around $10 \mu \mathrm{m}$ (Kim et al. 1985). Recent observations by the Infrared Space Observatory (ISO) have also identified benzene on Jupiter (Encrenaz et al. 1997). In addition, the Galileo probe mass spectrometer has detected traces of benzene (Niemann et al. 1998). The formation of benzene on Jupiter has been attributed to successive additive reactions involving $\mathrm{C}_{2} \mathrm{H}_{2}$ (Allen \& Yung 1985), but no detailed modeling has been reported. In particular, the energy source for the synthesis of ring compounds was not identified.

In this Letter, we present preliminary results of a chemical model of benzene and polycyclic aromatic hydrocarbons (PAHs) in the Jovian auroral region. We shall argue that charged energetic particles in addition to the enhanced auroral temperature are responsible for the production of benzene and PAHs. Our model, which incorporates the most important reaction pathways for synthesizing PAHs, is a combination of a photochemical model of hydrocarbons in the outer solar system and the $\mathrm{H}$ atom and ion chemistry of Perry et al. (1999).

\section{PHOTOCHEMICAL MODEL}

We base our model on the one-dimensional hydrocarbon photochemical model developed at Caltech/Jet Propulsion Laboratory (Gladstone, Allen, \& Yung 1996; Lee, Yung, \& Moses 2000). To this most comprehensive and recently updated model, we make four major modifications: (1) adding important reactions that produce PAHs; (2) including reactions that are the result of precipitating electrons; (3) using a temperature profile that is appropriate for the auroral region; and (4) taking into account the condensation of higher ring molecules. We use the same eddy diffusion coefficient as that used in the low-latitude model. The latitude of the polar model is $60^{\circ}$.

We add 98 PAH-related reactions to the model for the Jovian atmosphere. The most important reactions, along with kinetic rate constants, are summarized in Table 1. We adopt the no- menclature used by Wang \& Frenklach (1994). Our calculation includes aromatic molecules up to pyrene $\left(\mathrm{A}_{4}\right)$. The reaction scheme is adopted largely from laboratory and modeling studies in flame chemistry. In the absence of laboratory data for some reactions, we estimate their rate coefficients by analogy with known reactions. We use the same photodissociation coefficients for all $\mathrm{A}_{n}$, since the cross section data for the $n>1$ are unavailable. The major pathways for the formation of benzene and PAHs are shown in Figure 1.

The primary driving force for aerosol chemistry in the auroral atmosphere of Jupiter is dissociative recombination of methane ions that are produced from interaction with highenergy particles. Previous studies have shown that the power of the aurorae is in the range $10^{13}-10^{14} \mathrm{~W}$ and is greater than the EUV power from the Sun (see, e.g., Atreya 1986, § 6.3). Perry et al. (1999) have carried out electron transport calculations for the effects of precipitating electrons with a range of energies from 20 to $100 \mathrm{keV}$ and have presented dissociation and ionization rates of various ionic species. In our study, we adopt their calculated reaction rates (model B) for seven reactions involving the dissociative recombination reactions of $\mathrm{H}_{3}^{+}$and $\mathrm{CH}_{5}^{+}$, obtained from their Figure 4 (see reactions R315-321 in Table 1). The total input energy is about 11 ergs $\mathrm{cm}^{-2} \mathrm{~s}^{-1}$. The destruction rate of methane by precipitating electrons is about 25 times higher than that by photolysis at $60^{\circ}$.

Although there is no direct measurement of the temperature profile, the temperature in the auroral region is known to be much higher than that in nonauroral regions because of the heat deposition from precipitating particles. We use a temperature profile deduced by Trafton et al. (1994), which is consistent with observed rotational temperatures of $\mathrm{H}_{2}$ (Clarke et al. 1994; Liu \& Dalgarno 1996; Kim, Fox, \& Caldwell 1997). To reconcile the higher observed thermospheric temperature with the low temperature computed in the model of Perry et al. (1999), we suggest that the former is a sporadic phenomenon, whereas the model calculation is for the time-averaged atmosphere. Since the synthesis of PAHs occurs primarily during the transient high-temperature phase, the higher temperature profile should be more appropriate. 
TABLE 1

Partial List of Reactions and Rate Coefficients Used in Aerosol Chemistry Model

\begin{tabular}{|c|c|c|c|}
\hline Number & Reaction & Rate Coefficients & Reference \\
\hline R211 & $\mathrm{C}_{4} \mathrm{H}_{5}+\mathrm{C}_{2} \mathrm{H}_{2} \rightarrow l-\mathrm{C}_{6} \mathrm{H}_{6}+\mathrm{H}$ & $9.63 \times 10^{-16} T^{1.02} e^{-5489 / T}$ & 1 \\
\hline $\mathrm{R} 235 \ldots \ldots$ & $\mathrm{C}_{3} \mathrm{H}_{3}+\mathrm{C}_{3} \mathrm{H}_{3}+\mathrm{M} \rightarrow \mathrm{A}_{1}+\mathrm{M}$ & $k_{\infty}=1.66 \times 10^{-13 \mathrm{a}}$ & 1 \\
\hline $\mathrm{R} 241 \ldots \ldots$ & $\mathrm{C}_{4} \mathrm{H}_{3}+\mathrm{C}_{2} \mathrm{H}_{2} \rightarrow l-\mathrm{C}_{6} \mathrm{H}_{4}+\mathrm{H}$ & $6.14 \times 10^{-8} T^{-1.21} e^{-5589 / T}$ & 1 \\
\hline $\mathrm{R} 242 \ldots \ldots$ & $\mathrm{C}_{4} \mathrm{H}_{3}+\mathrm{C}_{2} \mathrm{H}_{2}+\mathrm{M} \rightarrow n-\mathrm{C}_{6} \mathrm{H}_{5}+\mathrm{M}$ & $k_{\infty}=7.08 \times 10^{-20} T^{1.97} e^{2820 / T \mathrm{a}}$ & 2 \\
\hline $\mathrm{R} 243 \ldots \ldots$ & $\mathrm{C}_{4} \mathrm{H}_{3}+\mathrm{C}_{2} \mathrm{H}_{2}+\mathrm{M} \rightarrow \mathrm{A}_{1^{-}}+\mathrm{M}$ & $k_{\infty}=3.82 \times 10^{44} T^{-17.65} e^{-12287 / T \mathrm{a}, \mathrm{b}}$ & 3 \\
\hline $\mathrm{R} 255 \ldots \ldots$ & $l-\mathrm{C}_{6} \mathrm{H}_{4}+\mathrm{H}+\mathrm{M} \rightarrow n-\mathrm{C}_{6} \mathrm{H}_{5}+\mathrm{M}$ & $k_{\infty}=5.48 \times 10^{20} T^{-10.04} e^{-9467 / T \mathrm{a}, \mathrm{b}}$ & 1 \\
\hline $\mathrm{R} 256 \ldots \ldots$ & $l-\mathrm{C}_{6} \mathrm{H}_{4}+\mathrm{H}+\mathrm{M} \rightarrow \mathrm{A}_{1-}^{-}+\mathrm{M}$ & $k_{\infty}=5.98 \times 10^{53} T^{-20.09} e^{-14150 / T \mathrm{a}, \mathrm{b}}$ & 1 \\
\hline $\mathrm{R} 258 \ldots \ldots$ & $n-\mathrm{C}_{6} \mathrm{H}_{5}+\mathrm{H} \rightarrow l-\mathrm{C}_{6} \mathrm{H}_{4}+\mathrm{H}_{2}$ & $2.49 \times 10^{-11}$ & 4 \\
\hline R259 ........ & $n-\mathrm{C}_{6} \mathrm{H}_{5}+\mathrm{H}+\mathrm{M} \rightarrow l-\mathrm{C}_{6} \mathrm{H}_{6}+\mathrm{M}$ & $k_{\infty}=1.83 \times 10^{18} T^{-9.65} e^{-3525 / T \mathrm{a}}$ & 4 \\
\hline $\mathrm{R} 261 \ldots \ldots$ & $l-\mathrm{C}_{6} \mathrm{H}_{6}+\mathrm{H} \rightarrow \mathrm{A}_{1}+\mathrm{H}$ & $1.44 \times 10^{-7} T^{-1.34} e^{-1762 / T}$ & 1 \\
\hline \multirow[t]{2}{*}{$\mathrm{R} 262 \ldots \ldots$} & $l-\mathrm{C}_{6} \mathrm{H}_{6}+\mathrm{H}+\mathrm{M} \rightarrow n-\mathrm{C}_{6} \mathrm{H}_{7}+\mathrm{M}$ & $k_{\infty}=2.49 \times 10^{-8} T^{-1.69} e^{-805.7 / T}$ & 1 \\
\hline & & $k_{0}=8.00 \times 10^{-31} T^{-0.52} e^{-503.6 / T}$ & 1 \\
\hline $\mathrm{R} 264 \ldots \ldots$. & $l-\mathrm{C}_{6} \mathrm{H}_{7}+\mathrm{M} \rightarrow \mathrm{A}_{1}+\mathrm{H}+\mathrm{M}$ & $1.39 \times 10^{-2} T^{-4.22} e^{-5690 / T}$ & 1 \\
\hline \multirow{2}{*}{ R265 …..... } & $\mathrm{A}_{1^{-}}+\mathrm{H}+\mathrm{M} \rightarrow \mathrm{A}_{1}+\mathrm{M}$ & $k_{\infty}=1.66 \times 10^{-10}$ & 4 \\
\hline & & $k_{0}=1.82 \times 10^{28} T^{-16.3} e^{-3526 / T}$ & 4 \\
\hline $\mathrm{R} 266 \ldots \ldots$ & $\mathrm{A}_{1^{-}}+\mathrm{C}_{2} \mathrm{H}_{2}+\mathrm{M} \rightarrow n-\mathrm{A}_{1} \mathrm{C}_{2} \mathrm{H}_{2}+\mathrm{M}$ & $k_{\infty}=1.28 \times 10^{17} T^{-9.19} e^{-6748 / T \mathrm{a}, \mathrm{b}}$ & 1 \\
\hline $\mathrm{R} 267 \ldots \ldots$. & $\mathrm{A}_{1}-+\mathrm{C}_{2} \mathrm{H}_{2} \rightarrow \mathrm{A}_{1} \mathrm{C}_{2} \mathrm{H}+\mathrm{H}$ & $1.25 \times 10^{3} T^{-3.96} e^{-861 / T \mathrm{~b}}$ & 4 \\
\hline $\mathrm{R} 270 \ldots \ldots$ & $\mathrm{A}_{1}+\mathrm{H} \rightarrow \mathrm{A}_{1^{-}}+\mathrm{H}_{2}$ & $4.15 \times 10^{-10} e^{-8057 / T}$ & 5 \\
\hline R273 .......... & $\mathrm{A}_{1} \mathrm{C}_{2} \mathrm{H}+\mathrm{H}+\mathrm{M} \rightarrow n-\mathrm{A}_{1} \mathrm{C}_{2} \mathrm{H}_{2}+\mathrm{M}$ & $k=1.66 \times 10^{30} T^{-12.76} e^{-8661 / T \mathrm{a}, \mathrm{b}}$ & 1 \\
\hline $\mathrm{R} 276 \ldots \ldots$ & $n-\mathrm{A}_{1} \mathrm{C}_{2} \mathrm{H}_{2}+\mathrm{C}_{2} \mathrm{H}_{2} \rightarrow \mathrm{A}_{2}+\mathrm{H}$ & $3.49 \times 10^{-9} T^{-1.07} e^{-2417 / T \mathrm{~b}}$ & 4 \\
\hline $\mathrm{R} 277 \ldots \ldots$ & $n-\mathrm{A}_{1} \mathrm{C}_{2} \mathrm{H}_{2}+\mathrm{H} \rightarrow \mathrm{A}_{1} \mathrm{C}_{2} \mathrm{H}+\mathrm{H}_{2}$ & $2.49 \times 10^{-11}$ & 4 \\
\hline $\mathrm{R} 285 \ldots \ldots$ & $\mathrm{A}_{2}-1+\mathrm{H}+\mathrm{M} \rightarrow \mathrm{A}_{2}+\mathrm{M}$ & $k_{\infty}=1.66 \times 10^{-10}, k_{0}=3.33 \times 10^{-12}$ & 4 \\
\hline R287 ......... & $\mathrm{A}_{2}-1+\mathrm{C}_{2} \mathrm{H}_{2}+\mathrm{M} \rightarrow \mathrm{A}_{2} \mathrm{C}_{2} \mathrm{H}_{2}+\mathrm{M}$ & $k_{\infty}=7.47 \times 10^{15} T^{-8.71} e^{-7201 / T \mathrm{a}, \mathrm{b}}$ & 1 \\
\hline $\mathrm{R} 288 \ldots \ldots$ & $\mathrm{A}_{2}-1+\mathrm{C}_{2} \mathrm{H}_{2} \rightarrow \mathrm{A}_{2} \mathrm{C}_{2} \mathrm{HA}+\mathrm{H}$ & $2.32 \times 10^{-2} T^{-2.64} e^{-8762 / T \mathrm{~b}}$ & 1 \\
\hline $\mathrm{R} 289 \ldots \ldots$ & $\mathrm{A}_{2}+\mathrm{H} \rightarrow \mathrm{A}_{2}-1+\mathrm{H}_{2}$ & $k_{289}=k_{270}$ & \\
\hline R293 ......... & $\mathrm{A}_{2} \mathrm{C}_{2} \mathrm{HA}+\mathrm{H}+\mathrm{M} \rightarrow \mathrm{A}_{2} \mathrm{C}_{2} \mathrm{H}_{2}+\mathrm{M}$ & $k_{\infty}=3.15 \times 10^{26} T^{-11.63} e^{-8158 / T \mathrm{a}, \mathrm{b}}$ & 1 \\
\hline $\mathrm{R} 294 \ldots \ldots$. & $\mathrm{A}_{2} \mathrm{C}_{2} \mathrm{H}_{2}+\mathrm{H} \rightarrow \mathrm{A}_{2} \mathrm{C}_{2} \mathrm{HA}+\mathrm{H}_{2}$ & $2.49 \times 10^{-11}$ & 4 \\
\hline R297 .......... & $\mathrm{A}_{2} \mathrm{C}_{2} \mathrm{H}_{2}+\mathrm{C}_{2} \mathrm{H}_{2} \rightarrow \mathrm{A}_{3}+\mathrm{H}$ & $k_{207}=k_{276}$ & \\
\hline $\mathrm{R} 303 \ldots \ldots$ & $\mathrm{A}_{3}-4+\mathrm{H}+\mathrm{M} \rightarrow \mathrm{A}_{3}+\mathrm{M}$ & $k_{\infty}=1.66 \times 10^{-10}, k_{0}=2.21 \times 10^{-14}$ & 4 \\
\hline $\mathrm{R} 304 \ldots \ldots$ & $\mathrm{A}_{3}+\mathrm{C}_{2} \mathrm{H} \rightarrow \mathrm{A}_{3} \mathrm{C}_{2} \mathrm{H}+\mathrm{H}$ & $8.30 \times 10^{-11}$ & 4 \\
\hline R305 …..... & $\mathrm{A}_{3}-4+\mathrm{C}_{2} \mathrm{H}_{2}+\mathrm{M} \rightarrow \mathrm{A}_{3} \mathrm{C}_{2} \mathrm{H}_{2}+\mathrm{M}$ & $k_{\infty}=1.11 \times 10^{22} T^{-10.55} e^{-10675 / T \mathrm{a}, \mathrm{b}}$ & 4 \\
\hline R306 .......... & $\mathrm{A}_{3}-4+\mathrm{C}_{2} \mathrm{H}_{2} \rightarrow \mathrm{A}_{2} \mathrm{C}_{2} \mathrm{H}+\mathrm{H}$ & $1.33 \times 10^{-6} T^{-1.21} e^{-11380 / T \mathrm{~b}}$ & 1 \\
\hline $\mathrm{R} 308 \ldots \ldots$ & $\mathrm{A}_{3} \mathrm{C}_{2} \mathrm{H}+\mathrm{H}+\mathrm{M} \rightarrow \mathrm{A}_{3} \mathrm{C}_{2} \mathrm{H}_{2}+\mathrm{M}$ & $k_{\infty}=8.63 \times 10^{23} T^{-11.05} e^{-7402 / T \mathrm{a}, \mathrm{b}}$ & 1 \\
\hline $\mathrm{R} 310 \ldots \ldots$ & $\mathrm{A}_{3} \mathrm{C}_{2} \mathrm{H}_{2}+\mathrm{M} \rightarrow \mathrm{A}_{4}+\mathrm{H}+\mathrm{M}$ & $1.12 \times 10^{25} T^{-11.86} e^{-14150 / T \mathrm{~b}}$ & 1 \\
\hline $\mathrm{R} 312 \ldots \ldots$ & $\mathrm{A}_{4}^{-}+\mathrm{H}+\mathrm{M} \rightarrow \mathrm{A}_{4}+\mathrm{M}$ & $k_{\infty}=1.66 \times 10^{-10 \mathrm{a}}$ & 4 \\
\hline $\mathrm{R} 315 \ldots \ldots$ & $\mathrm{H}_{3}^{+}+e \rightarrow \mathrm{H}_{2}+\mathrm{H}$ & $2.88 \times 10^{-8}(300 / T)^{0.65}$ & 6 \\
\hline $\mathrm{R} 316 \ldots \ldots$ & $\mathrm{H}_{3}^{+}+e \rightarrow \mathrm{H}+\mathrm{H}+\mathrm{H}$ & $8.63 \times 10^{-8}(300 / T)^{0.65}$ & 6 \\
\hline $\mathrm{R} 317 \ldots \ldots$ & $\mathrm{CH}_{5}^{+}+e \rightarrow{ }^{3} \mathrm{CH}_{2}+\mathrm{H}_{2}+\mathrm{H}$ & $5.3 \times 10^{-7}(300 / T)^{0.52}$ & 6 \\
\hline $\mathrm{R} 318 \ldots \ldots$ & $\mathrm{CH}_{5}^{+}+e \rightarrow \mathrm{CH}_{3}+\mathrm{H}+\mathrm{H}$ & $1.9 \times 10^{-8}(300 / T)^{0.52}$ & 6 \\
\hline $\mathrm{R} 319 \ldots \ldots$ & $\mathrm{CH}_{5}^{+}+e \rightarrow \mathrm{CH}_{3}^{+}+\mathrm{H}_{2}$ & $1.7 \times 10^{-8}(300 / T)^{0.52}$ & 6 \\
\hline $\mathrm{R} 320 \ldots \ldots$ & $\mathrm{CH}_{5}^{+}+e \rightarrow \mathrm{CH}_{4}+\mathrm{H}$ & $9.0 \times 10^{-9}(300 / T)^{0.52}$ & 6 \\
\hline $\mathrm{R} 321 \ldots \ldots$ & $\mathrm{CH}_{5}^{+}+e \rightarrow \mathrm{CH}+\mathrm{H}_{2}+\mathrm{H}_{2}$ & $9.5 \times 10^{-9}(300 / T)^{0.52}$ & 6 \\
\hline
\end{tabular}

Note. - The complete set includes all the relevant reactions considered by Gladstone et al. 1996, updated by Lee et al. 2000, and some other less important PAH reactions studied in this work. Units for two- and three-body rate coefficients are $\mathrm{cm}^{3} \mathrm{~s}^{-1}$ and $\mathrm{cm}^{6} \mathrm{~s}^{-1}$, respectively; $k_{0}$ and $k_{\infty}$ refer to the low and high pressure limits of the rate coefficients.

${ }^{\mathrm{a}} k_{0}=10^{-27}$, estimated.

${ }^{\mathrm{b}}$ Set at maximum value near $750 \mathrm{~K}$.

REFERENCES. - (1) Wang \& Frenklach 1994; (2) Colket 1986; (3) Westmoreland et al. 1989; (4) Wang \& Frenklach 1997; (5) Keifer et al. 1985; (6) Perry et al. 1999.

Ring compounds $\mathrm{A}_{1}$ through $\mathrm{A}_{4}$ are condensed when their vapor pressures are exceeded. We define the loss rate of a condensing species by a procedure described in Summers \& Strobel (1989), with a condensation time constant of $10^{6} \mathrm{~s}$. The vapor pressures are taken from Yaws (1994).

\section{RESULTS AND DISCUSSION}

The results of the model calculations are shown in Figure 2. Figure $2 a$ presents the mixing ratios for $\mathrm{CH}_{4}, \mathrm{C}_{2} \mathrm{H}_{6}, \mathrm{C}_{2} \mathrm{H}_{4}$, and $\mathrm{C}_{2} \mathrm{H}_{2}$. Compared with a solar-driven model at lower latitudes (Lee et al. 2000), the polar model has an order of magnitude more $\mathrm{C}_{2}$ hydrocarbons. The reason is the greater rate of $\mathrm{CH}_{4}$ dissociation, as discussed earlier. Figure $2 b$ shows that the maximum mixing ratio of benzene is $2 \times 10^{-9}$. This result is in fairly good agreement with the Voyager observation of $\left(2_{-1}^{+2}\right) \times 10^{-9}$ in the north polar auroral region (Kim et al. 1985).
Above $1 \mathrm{mb}$, the column density is $9.3 \times 10^{13} \mathrm{~cm}^{-2}$, which can be compared with the preliminary result of stratospheric midlatitude (not the auroral region) benzene column density at $2 \times 10^{14} \mathrm{~cm}^{-2}$ from the ISO observation (B. Bézard 1999, private communication).

We study the response of the model to various effects including temperature, precipitating electrons, and condensation. Using a much lower temperature profile from Voyager measurements, we find that the total benzene concentration does not vary much, although the production and destruction rates are both decreased by a factor of 10 . The concentrations of higher ring compounds $\mathrm{A} 2, \mathrm{~A} 3$, and $\mathrm{A} 4$ are decreased by factors of 2, 100, and 20,000, respectively. Without the ion-related reactions, benzene concentration is reduced by a factor of 550 . This confirms that the energetic particles are essential to benzene formation. Test runs show that $62 \%$ of the higher ring 

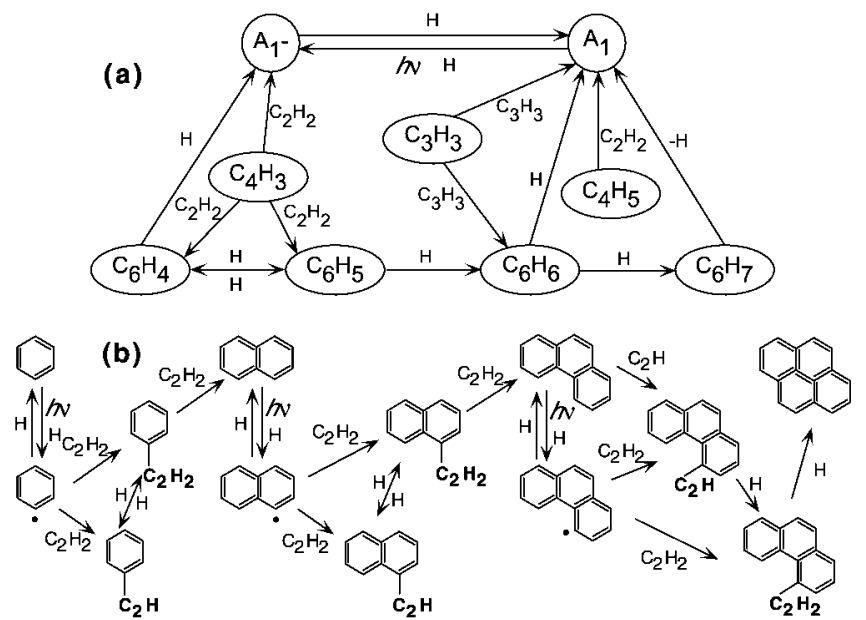

FIG. 1.-Schematic diagram showing the major pathways for (a) benzene $\left(\mathrm{A}_{1}\right)$ and $(b) \mathrm{A}_{2}, \mathrm{~A}_{3}$, and $\mathrm{A}_{4}$ formation in the auroral atmosphere of Jupiter.

molecules are condensed. The sensitivity of the benzene mixing ratio to the eddy diffusion coefficient will be tested in future works.

The total dissociation rate of $\mathrm{CH}_{4}$ in the model is $6.7 \times$ $10^{10}$ molecules $\mathrm{cm}^{-2} \mathrm{~s}^{-1}$. About $1 \%$ of this leads to the production of $\mathrm{A}_{n}$ species, resulting in a mass flux of about $10^{-14}$ $\mathrm{g} \mathrm{cm}^{-2} \mathrm{~s}^{-1}$. Polar haze particles occupy the region $\sim 0.3-50 \mathrm{mb}$ (West 1988; Pryor et al. 1991), probably concentrated near $10 \mathrm{mb}$ (R. A. West 1999, private communication). Assuming the particles have a mean radius of $0.1 \mu \mathrm{m}$, we estimate that a haze layer with optical depth of 0.1 in the near UV could be generated by the mass flux computed in our model. Our model yields for PAHs are considerably larger than what was generated in a laboratory study for Titan's atmosphere (Sagan et al. 1993).

\section{CONCLUSION}

Benzene was discovered over a decade ago, and the origin of polar aerosols on Jupiter has remained a puzzle for a long time. This is the first quantitative chemical model that attempts to simulate the production of aromatic compounds. Our simple model can account for most of the observations and suggests that the condensation of heavy aromatic molecules is a source for the aerosols. Our model can be tested by new observations. PAH concentrations should vary as the auroral temperature changes. The difference in benzene concentrations should be
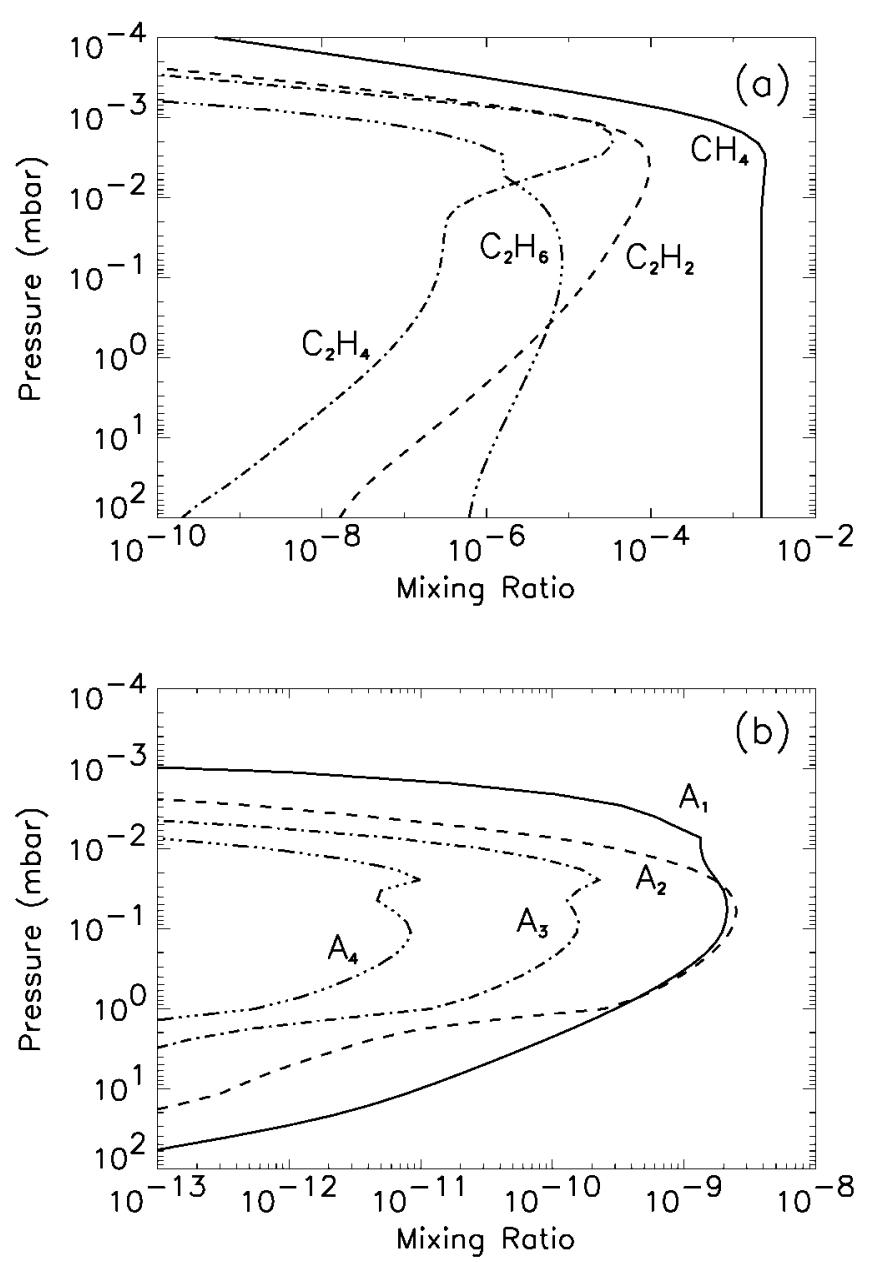

Fig. 2.-Hydrocarbon mixing ratio profiles as a function of pressure in the polar model for $(a) \mathrm{CH}_{4}, \mathrm{C}_{2} \mathrm{H}_{2}, \mathrm{C}_{2} \mathrm{H}_{4}$, and $\mathrm{C}_{2} \mathrm{H}_{6}$ and $(b) \mathrm{A}_{1}, \mathrm{~A}_{2}, \mathrm{~A}_{3}$, and $\mathrm{A}_{4}$.

observable at different latitudes, as the IRIS observations (Kim et al. 1985) suggested. More extensive observations of benzene and PAHs are needed to test our theory.

We thank R. A. West for discussion on the aerosol formation, B. Bézard for result on ISO observations, and M. Allen, M. F. Gerstell, and G. D. McDonald for helpful comments. This work was supported by NASA grants NAG5-6263 and NAG5-8257 and two grants to J. M. A. at JPL.

\section{REFERENCES}

Allen, M., \& Yung, Y. L. 1985, BAAS, 17, 710

Atreya, S. K. 1986, Atmospheres and Ionospheres of the Outer Planets and Their Satellites (New York: Springer)

Clarke, J. T., et al. 1994, ApJ, 430, L73

Colket, M. B. 1986, in 21st Symp. (Int.) on Combustion (Pittsburgh: Combustion Inst.), 851

Encrenaz, Th., et al. 1997, in Proc. First ISO Workshop on Analytical Spectroscopy, ed. M. Kessler (ESA-SP 419; Noordwijk: ESA), 125

Gladstone, G. R., Allen, M., \& Yung, Y. L. 1996, Icarus, 119, 1

Keifer, J. H., et al. 1985, J. Chem. Phys., 10, 2013

Kim, S. J., et al. 1985, Icarus, 64, 233

Kim, Y. H., Fox, J. L., \& Caldwell, J. J. 1997, Icarus, 128, 189

Lee, A. Y. T., Yung, Y. L., \& Moses, J. 2000, J. Geophys. Res., in press
Liu, W., \& Dalgarno, A. 1996, ApJ, 467, 446

Niemann, H. B., et al. 1998, J. Geophys. Res., 103, E22831

Perry, J. J., et al. 1999, J. Geophys. Res., 104, 16541

Pryor, J. R., et al. 1991, Icarus, 91, 161

Sagan, C. B., et al. 1993, ApJ, 414, 399

Summers, M. E., \& Strobel, D. F. 1989, ApJ, 346, 495

Trafton, L. M., et al. 1994, ApJ, 421, 816

Wang, H., \& Frenklach, M. 1994, J. Chem. Phys., 98, 11465 . 1997, Combustion. Flame, 110, 173

West, R. A. 1988, Icarus, 75, 381

Westmoreland, P. R., et al. 1989, J. Chem. Phys., 93, 8171

Yaws, C. L. 1994, Handbook of Vapor Pressure (Texas: Gulf Publishing) 